2017 V00 0: pp. 1-33

DOI: $10.1111 / 1540-6229.12210$

REAL Estate

ECONOMICS

\title{
The Dynamics of REIT Pricing Efficiency
}

\author{
Mike Aguilar, ${ }^{*}$ Walter I. Boudry** and Robert A. Connolly***
}

We study the dynamics of pricing efficiency in the equity REIT market from 1993 to 2014. We measure pricing efficiency at the firm level using variance ratios calculated from quote midpoints in the TAQ database. We find four main results. First, on average, the market is efficient, with variance ratios close to one. However, in any given year, there is considerable cross-sectional variation in variance ratios, suggesting at least some firms are priced inefficiently. Second, higher institutional ownership by active institutional investors is related to better pricing efficiency, while passive ownership does not reduce pricing efficiency. Third, REITs that are included in the S\&P 500 and S\&P 400 are priced more efficiently than other REITs. For the S\&P 500 firms, we find evidence that this was purely driven by sample selection, while for S\&P 400 firms, we find evidence that it is inclusion in the index that drives efficiency. Finally, we find evidence that firm investment, analyst coverage and debt capital raising activity can influence pricing efficiency.

\section{Introduction}

The efficiency of price discovery in the equity markets is of enduring interest, and this is no less true in the equity market for securitized real-estate (REITs). For many investors, particularly institutional investors who do not want to own buildings or land, real estate-related portfolio diversification is often undertaken in the REIT market. ${ }^{1}$ Price discovery is no less important for the managers themselves. The capital constrained nature of the REIT industry makes efficient access to capital a critical issue for the industry. As such, understanding the determinants of efficient pricing at the REIT level is important to both investors and managers alike.

\footnotetext{
*Department of Economics, University of North Carolina at Chapel Hill, Chapel Hill, NC or maguilar@email.unc.edu.

**School of Hotel Administration, Cornell SC Johnson College of Business, Cornell University, Ithaca, NY orwb242@ cornell.edu.

***Department of Finance, Kenan-Flagler Business School, University of North Carolina at Chapel Hill, Chapel Hill, NC or robert_connolly@unc.edu.
}

${ }^{1}$ See Boudry, deRoos and Ukhov (2016) for a discussion of the diversification benefits of REIT stock. 
Prior literature on REIT efficiency has focused on index-level returns. ${ }^{2}$ Consequently, the literature does not address important cross-sectional issues. For example, examining pricing efficiency at the firm level allows us to address the debate in the popular press about the effects of active versus passive institutional investors on pricing efficiency. ${ }^{3}$ This debate is particularly relevant for the REIT industry, because REIT ownership has become dominated by passive institutional investors since 2001, when REITs were first included in the major S\&P indices. Compared to the universe of non-REITs, REITs have approximately twice the level of passive institutional ownership.

With these motivations in mind, there have been several studies examining firm-level efficiency in the broader equities markets. ${ }^{4}$ However, these studies typically exclude REITs and other securities such as ADRs and ETFs. The question then becomes, are REITs different enough from the rest of the equities markets to warrant a separate investigation? We believe this is the case for several reasons. First, REITs are more transparent than regular firms. Part of the requirements in 26 U.S.C. $\$ 856$ for a firm to maintain REIT tax status are restrictions on asset ownership and income sources. The result of these restrictions is that the equity REITs in our sample hold commercial properties as their assets. The ability to price the firm's underlying assets (although in a somewhat illiquid secondary market) provides a degree of transparency not observed in a regular sample of firms. Greater transparency should lead to greater price efficiency. Second, REITs are heavily dependent on capital markets to fund investment due to their restrictive distribution requirements. Their reliance on capital markets to fund investment suggests that they may face higher levels of monitoring, which could improve efficiency. Third, REITs tend to be small to mid-cap in size. The size of the firms suggests that a poor market microstructure may play a role in their pricing efficiency. Finally, the industry has gone through massive structural changes since the early 1990s. Prior to this time, there were restrictions on institutional ownership and the industry was viewed as fairly unsophisticated. Probably, the best indication of this is that it was not until 2001 that REITs were eligible to join the major S\&P indexes. Taken together, these factors all suggest that REIT efficiency warrants its own investigation.

The first contribution of our article is to provide a comprehensive assessment of REIT market efficiency at the level of the individual REIT over the modern

\footnotetext{
${ }^{2}$ See, for example, Stevenson (2002) and Jirasakuldech and Knight (2005).

${ }^{3}$ See, for example, Krouse, Benoit and McGinty (2016).

${ }^{4}$ See Boehmer and Kelley (2009), O'Hara and Ye (2011) and Conrad, Wahal and Xiang (2015) for recent examples.
} 
REIT era. Prior firm-level studies typically focus on time periods before 1993 . At that time, the REIT market was characterized by microcap stocks and limited investor attention, vastly different from the REIT market today. We construct the cross-sectional empirical distribution of market efficiency using REIT-level variance ratios estimated using quarterly samples of intraday quote midpoints. Although complete data and computational details are provided later in the article, intuitively, the variance ratio exploits the fact that under the assumption of prices following a random walk, the variance of returns scale linearly with the holding period (the variance of $k$-period returns should be equal to $k$ times the variance of 1-period returns; hence, the ratio of the variance of $k$-period returns to $k$ times the variance of 1-period returns should be equal to one in an efficient market). The variance ratio is also related to return predictability. The two-period variance ratio can be shown to equal $1+\rho(1)$, where $\rho(1)$ is the first-order serial correlation coefficient of returns. Hence, a variance ratio of 1 implies no short-term return predictability. ${ }^{5} \mathrm{We}$ find that the mean of these distributions are centered very close to one, signaling average price efficiency. Yet, these distributions also show a high degree of excess kurtosis, indicating that a number of REITs appear to be inefficiently priced at any given point in time.

The second contribution of our article is to identify REIT-specific factors that account for the cross-sectional dynamics within the distribution of measured price efficiency. Although factors have been identified in research focused on equities generally (see Boehmer and Kelley 2009), there is, to the best of our knowledge, no comparable investigation in the REIT literature. We separate these factors into three categories: (1) Information Processing; (2) Information Production; and (3) Information Pricing. Information Processing factors, such as institutional ownership, relate to the ability to process information related to pricing. Information Production are factors, such as analyst coverage, that are related to greater availability of information about the firm. Information Pricing factors are microstructure variables that measure potential impediments, caused by the trading mechanism, to information being impounded into prices. Proxies for these categories need not be mutually exclusive. Institutional ownership could be related to both information processing (certain investors have a better ability to process information) and information production (certain institutions may have a greater ability to uncover price-relevant information).

\footnotetext{
${ }^{5}$ Our study focuses on short-horizon predictability using variance ratios. There is a literature examining long-horizon predictability, but it employs predictive regressions and is focused on time-varying expected returns rather than pricing efficiency. See Stambaugh (1999) and MacKinnon and Zaman (2009) for a recent application in real estate.
} 
We find several characteristics that drive REIT efficiency. First, as in Boehmer and Kelley (2009), we find that greater institutional ownership is related to increased pricing efficiency. However, unlike like Boehmer and Kelley (2009), this result is not driven by aggregate institutional ownership. Efficiency benefits are only observed for active ownership. We find a one standard deviation increase in ownership by funds in the top decile of portfolio turnover is associated with a $2.3 \%$ improvement in measured efficiency. While we do not find any robust evidence that passive institutional investors help improve efficiency, we also find no evidence to suggest that they reduce efficiency. Although the dramatic increase in institutional ownership observed in the REIT market since 2001 has been driven largely by passive investors, this has not led to a decrease in pricing efficiency in the market.

Second, REITs included in the S\&P 500 and S\&P 400 are priced more efficiently than other REITs, while there is no effect for the small-cap S\&P 600. In terms of economic magnitude, S\&P 500 firms are on average $25 \%$ more efficient and S\&P 400 firms are on average $15 \%$ more efficient than other firms. To address the issue of identification - that indexes may choose to only include efficient firms-we examine pre- and postinclusion efficiency in small windows around the index addition date. We find no significant difference in efficiency for S\&P 500 firms or for S\&P 600 firms, but there is a significant improvement in efficiency for S\&P 400 firms. This suggests REITs added to the S\&P 500 were already priced efficiently. However, inclusion in the mid-cap S\&P 400 is a significant event. The likely explanation for this is that addition to this index takes a firm from small-cap obscurity and places it on the investment screens of more investors.

Third, we find some evidence that information providers can improve the pricing efficiency of REITs. More analyst coverage is associated with improved pricing efficiency. This is consistent with results found for general equities, but somewhat contradicts some previous results in the REIT literature. While Boehmer and Kelley (2009) find analyst coverage to have beneficial effects for general equities, Downs and Güner $(1999,2000)$ find that greater analyst coverage in REITs tends to be associated with lower liquidity. In this case, we would expect inferior pricing efficiency. We believe that this result is largely driven by the time period examined. Downs and Güner (1999, 2000) cover only the earliest part of our sample period, and our results related to the changing dynamics of REIT efficiency highlight how difficult it can be to extrapolate results from earlier sample periods to the current REIT market.

Finally, we document that firm investment activity can impact efficiency. In our sample, a one standard deviation increase in investment or 
divestment activity is associated with a $3.8 \%$ improvement in pricing efficiency.

In the next section, we provide more detail on the existing literature, including papers from both the equity market microstructure and the REIT market research areas. The section "Data and Methods" explains our research design in detail, and also discusses our dataset and measurement issues. We present the basic picture of REIT market efficiency in the section "REIT Efficiency over Time." The section "Determinants of Efficiency Dynamics" extends the analysis to consider what REIT-level and market factors are associated with REIT-level efficiency dynamics. We summarize our findings in the final section.

\section{Previous Literature}

Our article is primarily related to two strands of literature. The first of these examines the efficiency of the REIT market, while the second examines the drivers of efficiency in general equities markets.

Real estate price discovery and the information aggregation process is central to the efficient operation of public real estate markets. A number of papers explore the efficiency of both U.S. and international REIT markets, although these papers almost exclusively focus on market-level implications and make no real examination of the cross section. The results in this literature have been mixed. Seck (1996) examines the substitutability of direct and securitized real estate and finds that while direct real estate is inefficient, securitized real estate is priced efficiently at the index level. Nelling and Gyourko (1998) examine runs tests for a sample of REITs and find that although some REITs appear to be priced inefficiently, the market as a whole appears efficient. Jirasakuldech and Knight (2005) examine REIT index-level returns and are unable to reject the null hypothesis of a random walk using variance ratio tests. Schindler, Rottke and Füss (2010) also support this conclusion for U.S. data, but show that internationally, most securitized real estate markets reject the null hypothesis of a random walk. These results contrast with Kuhle and Alvayay (2000), who find the majority of individual REITs deviate significantly from a random walk, suggesting large-scale inefficiency in the market. In general, the results reported in the literature are quite sensitive to the frequency of data employed, the time period examined and the form of tests used.

The article most closely related to this one is Boehmer and Kelley (2009). They examine the cross section of measured price efficiency for an extensive sample of general equities (excluding REITs). Their primary focus is on the 


\section{Aguilar, Boudry and Connolly}

relationship between institutional ownership and price efficiency. They find that higher institutional ownership leads to better pricing efficiency.

\section{Data and Methods}

To examine firm-level efficiency in the REIT market, we start with a list of equity REITs included in the SNL Financial universe between 1993 and 2014. We then match this list to the TAQ dataset. The TAQ dataset begins in 1993, so this places a limit on the historic sample. However, given that 1993 also represents essentially the start of the modern REIT era, it is also the logical starting point from any examination of REIT efficiency. For this sample, we develop a comprehensive database of REIT trading from which we extract appropriate measures of the efficiency of price setting and market quality. With these measures in hand, we document the evolution of REIT market efficiency at the REIT level. Our work moves past efficiency "on average," in favor of exploiting the entire distribution of measured REITlevel efficiency across the 1993-2014 period. We then exploit the model proposed by Boehmer and Kelley (2009) to study the cross section of market efficiency in the REIT market.

\section{Measuring Market Efficiency}

In an efficient market, price movements should approximate a random walk. Though myriad approaches to measuring efficiency exist, we follow O'Hara and Ye (2011), Boehmer and Kelley (2009) and Conrad, Wahal and Xiang (2015), and rely on a variance ratio calculation. As developed in Lo and Mackinlay (1988), the variance ratio test exploits the fact that the variance of random walk increments is linear in the sampling interval. ${ }^{6}$ Consider the $n q+1$ element $\log$ price series $\left\{p_{0}, p_{1}, \ldots, p_{n q}\right\}$ where $q$ is any integer greater than one. Define the following estimators:

$$
\begin{aligned}
& \hat{\mu}=\frac{1}{n q} \sum_{k=1}^{n q}\left(p_{k}-p_{k-1}\right), \\
& \bar{\sigma}_{a}^{2}=\frac{1}{n q-1} \sum_{k=1}^{n q}\left(p_{k}-p_{k-1}-\hat{\mu}\right)^{2}, \\
& \bar{\sigma}_{c}^{2}(q)=\frac{1}{m} \sum_{k=q}^{n q}\left(p_{k}-p_{k-q}-q \hat{\mu}\right)^{2},
\end{aligned}
$$

\footnotetext{
${ }^{6}$ See Campbell, Lo and MacKinlay (1997) for a textbook treatment.
} 
where $\hat{\mu}$ is the estimated mean of the $\log$ price increments, $\bar{\sigma}_{a}^{2}$ is the unbiased estimator of the variance of the 1-period $\log$ price increments and $\bar{\sigma}_{c}^{2}(q)$ is $1 / q$ times the unbiased estimator of the variance of the overlapping $q$-period $\log$ price increments, where $m=q(n q-q+1)\left(1-\frac{q}{n q}\right)$. The variance ratio is then calculated as

$$
\overline{V R}(q)=\frac{\bar{\sigma}_{c}^{2}(q)}{\bar{\sigma}_{a}^{2}} \text {. }
$$

For $q=2$, the variance ratio is equal to $1+\rho(1)$, where $\rho(1)$ is the first-order autocorrelation coefficient of the log price increments. If an asset follows a random walk, then $\rho(1)=0$, suggesting that the $V R$ should be equal to 1 . If the $V R$ is less than one, it signals mean reversion in returns, whereas a $V R$ greater than one signals momentum.

Lo and Mackinlay (1988) show that in the presence of heteroskedasticity, the test statistic for the null hypothesis of uncorrelated increments is

$\psi^{*}(q)=\frac{\sqrt{n q}(\overline{V R}(q)-1)}{\sqrt{\hat{\theta}}} \stackrel{a}{\sim} N(0,1)$,

where $\hat{\theta}=4 \sum_{k=1}^{q-1}\left(1-\frac{k}{q}\right)^{2} \hat{\delta}_{k}$, and $\hat{\delta}_{k}=\frac{n q \sum_{j=k+1}^{n q}\left(p_{j}-p_{j-1}-\hat{\mu}\right)^{2}\left(p_{j-k}-p_{j-k-1}-\hat{\mu}\right)^{2}}{\left[\sum_{j=1}^{n q}\left(p_{j}-p_{j-1}-\hat{\mu}\right)^{2}\right]^{2}}$.

In calculating the variance ratio $\overline{V R}(q)$, the choice of data frequency (the time interval at which the price increments $p_{k}$ are observed) and the number of periods, $q$, are choices of the econometrician. Our choices are driven by a desire to capture high-frequency dynamics of the price process, without being subject to microstructure noise. Conrad, Wahal and Xiang (2015) define their sampling intervals as 15 seconds, which we could mimic, but only for the years 2006-2014. Prior to this period of time, we do not observe quotes frequently enough to construct a reliable sequence of 15 -second price increments. Instead, we follow O'Hara and Ye (2011) by setting our return horizon equal to 15 minutes, and the number of periods, $q$, to 2 . This implies that the variance ratio compares 15-30-minute log price increments. We believe that this strikes a reasonable balance and it permits us to track efficiency consistently over our entire sample. ${ }^{7}$

\footnotetext{
${ }^{7}$ We also examined 15 -minute versus 60 - and 120 -minute increments, and found no appreciable difference.
} 
We recognize the vast literature documenting the weaknesses involving inferences based on standard variance ratio tests. ${ }^{8}$ As such, the reader should use care when interpreting our inference results. However, the focus of our article is not one of inference directed narrowly at whether prices of an individual REIT follow a random walk. Rather, our focus is in documenting the variation in, and drivers of, efficiency over time and in the cross section.

\section{Trades versus Quotes}

The intraday TAQ data include both the complete record of trades and the quote history for each day for each REIT. It is possible to calculate variance ratios using either traded prices or quote midpoints. The potential problem with using traded prices is induced negative serial correlation in prices because of bid-ask bounce. The essence of bid-ask bounce is trades take place either at the bid or at the ask price. This dichotomy creates price variation that reflects the size of the bid-ask spread, but is otherwise unrelated to fundamental value. As shown by Roll (1984) and Niederhoffer and Osborne (1966), bidask bounce induces a negative serial correlation in the observed price series, as the price bounces from one boundary to the other (i.e., bounces from the bid to the ask price and then back again). Empirically, Kaul and Nimalendran (1990) show that these effects can be quite severe when estimating variance ratios of small firms using transactions prices. Given the small-cap to mid-cap nature of the REIT universe, this problem is likely to be quite severe in our sample. ${ }^{9}$ For this reason, we follow Boehmer and Kelley (2009) and Conrad, Wahal and Xiang (2015) and employ quote midpoints, rather than prices, to estimate variance ratios. To calculate the series of quote midpoints, we employ the methodology of Holden and Jacobsen (2014). Using bid-to-bid prices as in Kaul and Nimalendran (1990) would also alleviate bid-ask bounce induced serial correlation, but because trades are reported less frequently than quotes, this would limit our ability to estimate higher frequency pricing dynamics, especially early in our sample.

\footnotetext{
${ }^{8}$ The primary problem in the VR test is that the finite sample distribution of the test statistic is unknown. This is due to the fact that the VR test is most often implemented with a rolling sample (as suggested by Lo and Mackinlay 1988) to improve power during inference. The sampling distribution is proxied by the limiting distribution, which may not be accurate, and this can create size distortions or low power, thereby generating misleading conclusions during inference. See Charles and Darne (2009) for a discussion.

${ }^{9}$ This may in part explain the mixed results in the prior literature on REIT efficiency. These papers use traded prices, and depending on the frequency of prices and time period examined, much of the deviation from random walks may be explained by bid-ask bounce. In unreported analysis, we calculated variance ratios using traded prices and do observe severe serial correlation, especially in the start of the sample examined.
} 


\section{REIT Efficiency over Time}

In this section, we document the time-series dynamics of pricing efficiency in the REIT market over the period 1993-2014. For each quarter in our sample, we compute the variance ratio for each REIT. Due to the natural birth and death process of REITs, we are left with an unbalanced panel of variance ratios. In total there are 251 unique REITs in the sample between 1993 and 2014. The number of firms in the sample in each year can be observed in Table 1 in the column labeled Firms.

Table 1 . Variance ratios by year.

\begin{tabular}{lccccccl}
\hline \hline \multicolumn{2}{l}{ Variance Ratio } & & & & & & \\
\hline Year & Firms & Obs & Mean & Std & Min & Max & Significant \\
\hline 1993 & 38 & 111 & 0.976 & 0.053 & 0.757 & 1.102 & 0.16 \\
1994 & 95 & 311 & 0.980 & 0.051 & 0.799 & 1.145 & 0.16 \\
1995 & 121 & 449 & 0.968 & 0.067 & 0.503 & 1.217 & 0.23 \\
1996 & 124 & 485 & 0.968 & 0.054 & 0.553 & 1.204 & 0.21 \\
1997 & 125 & 485 & 0.973 & 0.060 & 0.753 & 1.213 & 0.23 \\
1998 & 135 & 512 & 0.983 & 0.063 & 0.559 & 1.143 & 0.19 \\
1999 & 130 & 509 & 0.965 & 0.058 & 0.754 & 1.246 & 0.24 \\
2000 & 125 & 490 & 0.957 & 0.066 & 0.615 & 1.219 & 0.29 \\
2001 & 117 & 460 & 0.969 & 0.067 & 0.699 & 1.201 & 0.23 \\
2002 & 112 & 434 & 0.995 & 0.086 & 0.751 & 1.231 & 0.28 \\
2003 & 109 & 416 & 0.948 & 0.067 & 0.760 & 1.137 & 0.37 \\
2004 & 113 & 432 & 0.945 & 0.077 & 0.702 & 1.203 & 0.38 \\
2005 & 117 & 452 & 0.967 & 0.066 & 0.726 & 1.150 & 0.27 \\
2006 & 108 & 422 & 0.948 & 0.059 & 0.596 & 1.096 & 0.29 \\
2007 & 96 & 381 & 0.969 & 0.057 & 0.739 & 1.152 & 0.14 \\
2008 & 94 & 375 & 0.959 & 0.063 & 0.750 & 1.463 & 0.24 \\
2009 & 93 & 371 & 0.994 & 0.050 & 0.762 & 1.144 & 0.12 \\
2010 & 98 & 385 & 0.975 & 0.054 & 0.694 & 1.114 & 0.14 \\
2011 & 103 & 401 & 0.974 & 0.050 & 0.491 & 1.131 & 0.07 \\
2012 & 105 & 404 & 0.961 & 0.082 & 0.477 & 1.097 & 0.17 \\
2013 & 111 & 425 & 0.962 & 0.101 & 0.490 & 1.142 & 0.21 \\
2014 & 118 & 454 & 0.962 & 0.099 & 0.506 & 1.142 & 0.19 \\
\hline
\end{tabular}

Note: This table reports descriptive statistics of quarterly variance ratios by year. The quarterly variance ratios are calculated as in (4), where the frequency of sampling of price increments is 15 minutes and $q$ equals 2 , so that the variance ratio compares the variance of 30-minute returns calculated over the quarter and the variance of 15-minute returns calculated over the quarter. Returns are calculated from quote midpoints, which are calculated from TAQ data using the methods of Holden and Jacobsen (2014). "Significant" is the percentage of variance ratio tests (5) that can be rejected at the $5 \%$ level of significance. 


\section{Characterizing the Empirical Distribution}

How efficient is the REIT market on average? Do many REITs deviate from a variance ratio of 1 ? If so, how does efficiency evolve over time? To address these questions, we construct the quarterly variance ratios for each REIT trading in a given year, and repeat for each year from 19932014. For each year in the sample, these distributions are depicted in Figure 1. The first thing to note is that the center mass of these distributions is consistently near one, indicating the typical REIT appears efficient. However, we do observe the distribution of variance ratios appears to differ across years. Some years, such as 2009 , are very tightly centered around one, while other years, such as 1998, have long left tails. Even within a year like 2009 where the distribution is heavily centered at one, we still observe considerable cross-sectional variation. This suggests that efficiency is dynamic in nature. To address this more precisely, we conduct a two-sample Kolomogorov-Smirnov (K-S) test of equal empirical distributions for each pair of adjacent years. For instance, we compare the empirical distribution of 1994 to that of 1995 . The $p$-value of the K-S test statistic for that comparison is 0.011 , suggesting that we can reject the null of equal empirical distributions. We repeat this test for each of the 21 pairs of adjacent years, and find that we are able to reject the null at the 5\% level for 16 of the 21 pairwise comparisons. These test results suggest that the distributions do indeed change over time.

The visual findings in Figure 1 are corroborated by the summary statistics provided in Table 1, where we report the descriptive statistics of the quarterly variance ratios by year. In the column headed "significant," we report the percentage of variance ratio tests for that year that reject the null hypothesis of a random walk at the 5\% level of significance. In each year, we observe that the mean variance ratio is close to one. The lowest average variance ratio occurs in 2004 with a value of 0.945 , while the highest average occurs in 2002 with an average variance ratio of 0.995 . In each year, we observe a substantial range of variance ratios, with the lowest and highest variance ratios in any given year differing by approximately 0.5 . The variance ratio tests corroborate this. In total, $22.4 \%$ of the variance ratio tests reject the null hypothesis of a random walk at the 5\% level of significance. However, this percentage is not constant across years, with a low of $7.1 \%$ in 2011 and a high of $38.0 \%$ in 2004 . These tests provide further evidence that efficiency in the REIT market is dynamic in nature. 

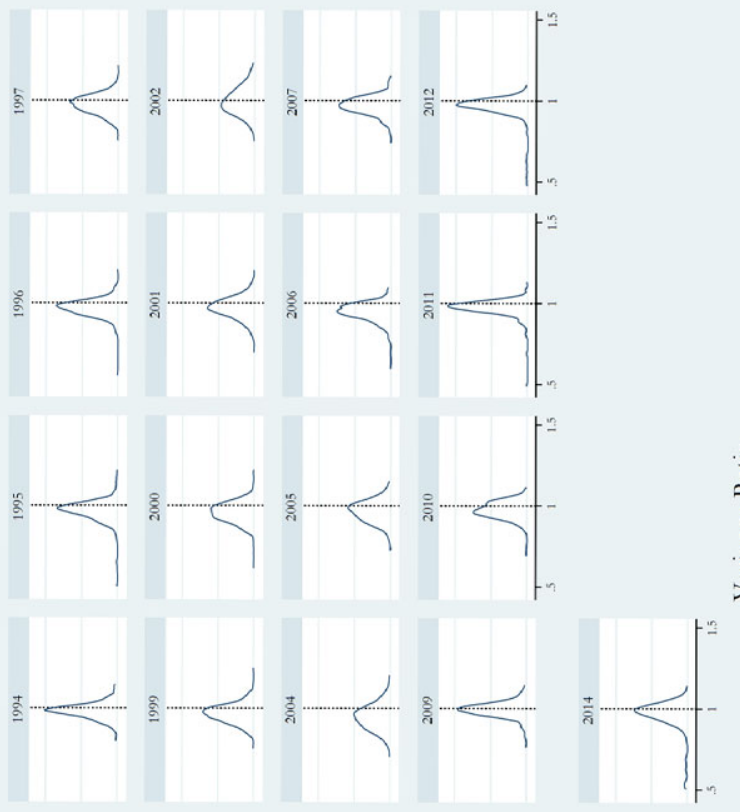

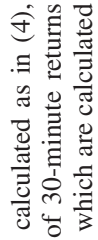

जั :

웛

ชั

可

늠

额

言递

웛

需苛

$\stackrel{x}{>}$

วิ올

현

焉焉

तi

홓 노 올

त 힝

जo

焉宁

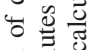

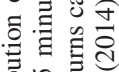

言约总

:
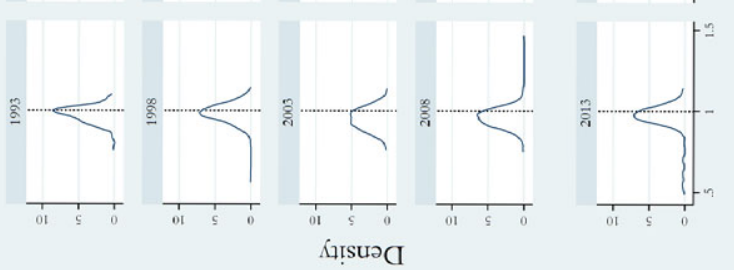

记声导

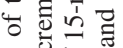

흐유

음 \& 응

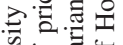

可

on $\&$ :

ए)

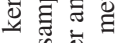

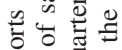

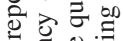

D

品导离苛

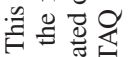

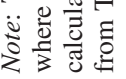




\section{Determinants of Efficiency Dynamics}

In this section, we explore the factors that drive the cross-sectional dynamics within the distribution of measured price efficiency. We begin by discussing the model and estimation in the first subsection, the data in the second subsection, followed by results of panel regressions in the final subsection.

\section{Model and Estimation}

The empirical approach we use largely reflects the work of Boehmer and Kelley (2009). The main empirical obstacle in examining firm efficiency is the obvious potential for endogeneity. For instance, it is possible that institutional ownership leads to higher levels of efficiency through a standard information production channel. However, it is also possible that institutions just have a preference for investing in efficient firms. Lacking a clean natural experiment, the standard approach in the literature has been to regress current measures of efficiency on the lagged dependent variable and lagged explanatory variables:

$|1-V R|_{i, t}=\alpha+\beta|1-V R|_{i, t-1}+\gamma_{k} X_{i, t-1}+\epsilon_{i, t}$,

where $|1-V R|_{i, t}$ is the absolute value of one minus the variance ratio of firm $i$ in period $t$, and $X_{i, t-1}$ is a vector of $K$ explanatory variables related to firm $i$ in period $t-1$. Given the unbalanced panel nature of the sample, we estimate (6) using a fixed effects panel regression model.

Employing raw variance ratios as the dependent variable in (6) is problematic because variance ratios both greater and less than one signal inefficiency. To address this, we follow Boehmer and Kelley (2009) and employ $|1-V R|$ $* 100$ as our dependent variable. For this variable, larger values are related to higher levels of inefficiency; either mean reverting or momentum.

In Table 2, we report descriptive statistics for $|1-V R|^{*} 100$ by year. As with the case of the raw variance ratios in Table 1, we observe both time-series and cross-sectional variation. We observe the lowest level of average pricing inefficiency in 2009 and the highest level in 2004. In each year, we observe considerable variation in inefficiency.

There are several candidates for explanatory variables, $X$, in this framework. We divide them into four groups: institutional ownership, index inclusion, information pricing and information production. 
Table 2 a Pricing efficiency by year.

\begin{tabular}{llllll}
\hline \hline$|1-\mathrm{VR}|^{*} 100$ & & & & & \\
\hline Year & Obs & Mean & Std & Min & Max \\
\hline 1993 & 111 & 4.191 & 3.989 & 0.043 & 24.323 \\
1994 & 311 & 4.059 & 3.584 & 0.002 & 20.099 \\
1995 & 449 & 5.134 & 5.352 & 0.012 & 49.680 \\
1996 & 485 & 4.688 & 4.174 & 0.003 & 44.650 \\
1997 & 485 & 5.076 & 4.087 & 0.002 & 24.682 \\
1998 & 512 & 4.749 & 4.500 & 0.032 & 44.065 \\
1999 & 509 & 5.274 & 4.188 & 0.009 & 24.603 \\
2000 & 490 & 6.084 & 5.051 & 0.003 & 38.503 \\
2001 & 460 & 5.665 & 4.641 & 0.011 & 30.076 \\
2002 & 434 & 6.847 & 5.167 & 0.030 & 24.923 \\
2003 & 416 & 6.756 & 5.094 & 0.005 & 23.984 \\
2004 & 432 & 7.641 & 5.586 & 0.001 & 29.805 \\
2005 & 452 & 5.807 & 4.583 & 0.004 & 27.350 \\
2006 & 422 & 6.074 & 5.079 & 0.020 & 40.417 \\
2007 & 381 & 4.998 & 4.127 & 0.010 & 26.114 \\
2008 & 375 & 5.733 & 4.836 & 0.007 & 46.331 \\
2009 & 371 & 3.656 & 3.425 & 0.020 & 23.833 \\
2010 & 385 & 4.682 & 3.773 & 0.028 & 30.553 \\
2011 & 401 & 3.747 & 4.251 & 0.009 & 50.909 \\
2012 & 404 & 5.049 & 7.549 & 0.007 & 52.256 \\
2013 & 425 & 6.279 & 8.834 & 0.005 & 51.013 \\
2014 & 454 & 6.084 & 8.635 & 0.025 & 49.363 \\
\hline
\end{tabular}

Note: This table reports descriptive statistics of quarterly pricing efficiency by year. Pricing efficiency is measured as $|1-V R|^{*} 100$, where $V R$ is the quarterly variance ratio. The quarterly variance ratios are calculated as in (4), where the frequency of sampling of price increments is 15 minutes and $q$ equals 2 , so that the variance ratio compares the variance of 30-minute returns calculated over the quarter and the variance of 15-minute returns calculated over the quarter. Returns are calculated from quote midpoints, which are calculated from TAQ data using the methods of Holden and Jacobsen (2014).

\section{Ownership}

One dimension along which REITs potentially differ from other public companies is institutional ownership. Part of the requirements in 26 U.S.C. \$856(a)(6) for a firm to maintain its REIT status is diverse ownership. The requirement is that at no time during the second half of the year can five or fewer individuals own, directly or indirectly, $50 \%$ or more of the REIT. This effectively limits the ability of owners to build large block positions in the firm. In 1993, a look-through provision was enacted with regard to the closely held stock rule, which relaxed this restriction for pension 
funds. ${ }^{10}$ Although not as binding a constraint as it once was due to the 1993 look-through provision, REITs typically will have ownership restrictions as part of their corporate charter to avoid conflicting with the closely-held stock rule.

Although the regulation related to institutional ownership is different in REITs compared to other public companies, the role of institutional investors is the same. In our context, informed trading refers to the trader's ability to acquire and accurately assimilate information regarding the firm's value. Prior studies such as Ke and Petroni (2004) and Yan and Zhang (2009) find institutions do appear to behave in a way that suggests they are better informed. All else equal, we expect stocks with a higher proportion of informed trading to generate higher informational efficiency, and thus a variance ratio closer to 1 . The focus on institutional ownership in the Boehmer and Kelley (2009) model is based upon the informational advantage of institutional traders. This advantage may come from access to privileged information (e.g., "insider" information) and/or from the professional investor's enhanced ability to process information. Regardless of the source, more institutional investors suggest more efficient trading. Countering this is the possibility that if institutions are pure "indexers," they are unlikely to provide any informational benefits.

To measure institutional ownership, we follow the methodology proposed by Yan and Zhang (2009) and calculate four institutional ownership variables using the underlying ownership data from Thomson Financial's $13 \mathrm{f}$ database. ${ }^{11}$ This dataset includes ownership by managers meeting the reporting criteria in 17 C.F.R. \$240.13f-1, which includes what we typically think of as institutional investors (e.g., hedge funds, mutual funds, pension funds, insurance companies and ETFs.) Total institutional ownership (TIO) is the level of ownership by all institutions. We then decompose the total level of institutional ownership into three components based on the frequency of trading of the underlying institutions. Short-term institutional ownership (SIO) is the percentage ownership of the REIT held by institutions in the top decile

\footnotetext{
${ }^{10}$ See Downs (1998) for a discussion of the rule change and the situation that led up to it.

${ }^{11}$ Studies focusing on REIT institutional ownership tend to categorize institutions by their legal type (bank, pension fund, investment company, etc.). See, for example, Devos et al. (2013) and Ciochetti, Craft and Shilling (2002). One exception is An, Wu and $\mathrm{Wu}(2016)$ who use the classification system of Bushee (1998), which relies on the underlying behavior of the institutional investors. In unreported results, an examination of ownership by different legal types shows that ownership by different legal types looks quite similar between REITs and non-REITs with both being dominated by institutional investment advisors.
} 
Figure 2 a Institutional ownership.

[Color figure can be viewed at wileyonlinelibrary.com]

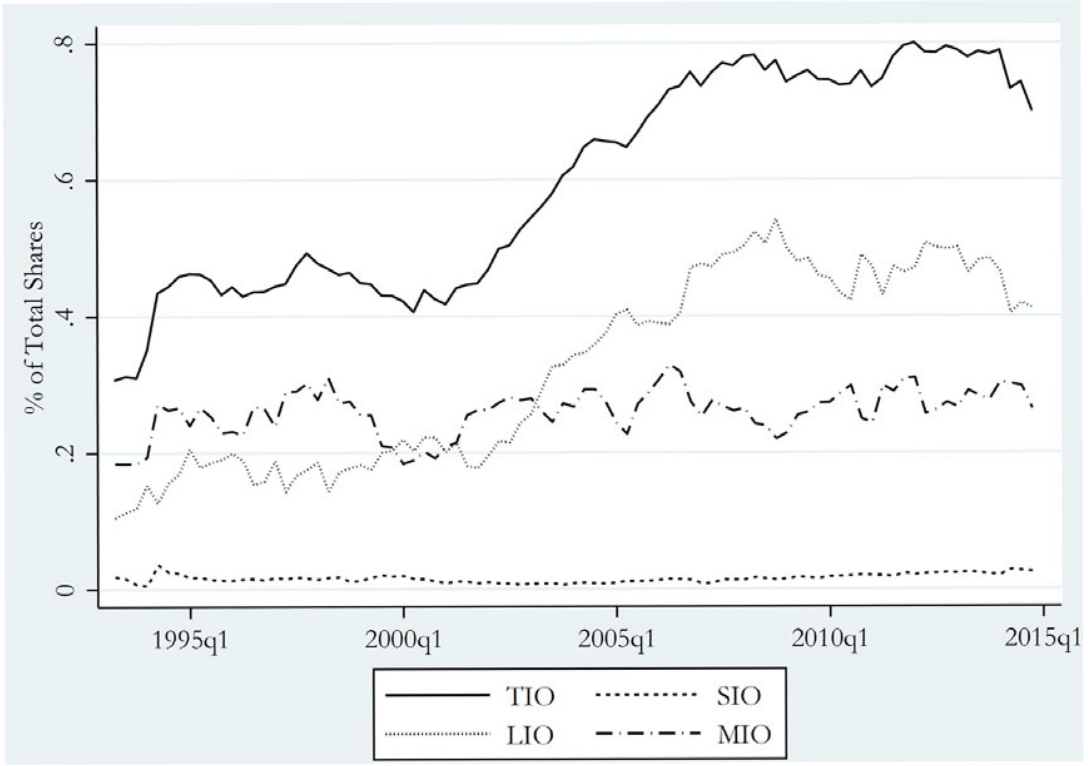

Note: This figure plots the average level of institutional ownership by quarter from 1993 to 2014. $T I O, S I O, M I O$ and $L I O$ are the percentage of shares held by all institutional owners, owners in the top decile of portfolio turnover, owners with above-median portfolio turnover (excluding the top decile) and owners with below-median portfolio turnover. TIO, SIO, MIO and LIO are calculated using the method proposed by Yan and Zhang (2009). Underlying ownership data come from Thomson Reuter's 13(f) database.

of portfolio turnover, long-term institutional ownership (LIO) is the percentage ownership of the REIT held by institutions with below-median portfolio turnover and medium-term institutional ownership (MIO) is the percentage of ownership of the REIT held by institutions with above-median portfolio turnover (excluding the top decile). If information is impounded into asset prices through active trading, it is possible that what matters for efficiency is the level of ownership held by the most active traders.

Figure 2 plots the average level of institutional ownership through time for the sample. As is evident in the figure, the level of TOI in the sample has increased through time. The likely explanation for the long-term trend is that our sample covers what is commonly referred to as the "modern REIT era." During this period of time, the REIT industry has expanded and has become more integrated with the broader capital markets. Because REITs are 
capital-constrained due to their high payout requirements, they need to raise capital to invest. ${ }^{12}$ Thus, industry expansion has gone hand in hand with broader capital markets integration.

Notice that this increase in ownership has been driven by low turnover institutions. While the holdings of institutions with above-median portfolio turnover have remained fairly constant, holdings by below-median turnover institutions have increased dramatically. This is especially true for the period after 2001, when REITs became eligible for inclusion in major S\&P indices. In this sense, the figure demonstrates the dramatic rise in the indexation of the REIT market.

To further examine this issue, we calculate the level of TIO, SIO, MIO and LIO for the universe of non-REIT firms over the same time period. While TIO trends upward for both samples, REITs have dramatically higher TIO at the end of the sample period than non-REITs $(70.0 \%$ vs. $44.5 \%)$. This is driven by the increase in LIO in the REIT market post-2001. By the end of the sample, $42.0 \%$ of REIT shares are held by passive institutions, while this figure is only $22.4 \%$ for non-REITs. Interestingly, the average level of ownership by extremely active institutions is quite similar across both samples.

In Table 3, we report descriptive statistics for $S I O, M I O$ and $L I O$ by year for the sample. The overall increasing trend in institutional ownership among REITs is quite evident, but so is the high degree of cross-sectional variation. Even in the early part of the sample when the REIT industry was quite small, we still observe firms with high institutional ownership. Interestingly, this tended to be because of more active institutional owners as opposed to passive owners. The rise in passive owners coincides with inclusion of the REITs in the S\&P indices in 2001. Between 2001 and 2014, the average level of $L I O$ more than doubled going from $19.2 \%$ to $42 \%$. During the same time period, the growth in ownership by short-term and medium-term owners was much more modest. The average level of SIO increased from $1.0 \%$ to $2.5 \%$, while the average level of $M I O$ increased from $23.5 \%$ to $28.8 \%$. The net result being that ownership by passive institutional owners dominates the market by the end of the sample period. Although passive owners dominate the sample, at the firm level we observe some firms that have little passive ownership and others that have a quarter of their shares held by highly active institutional traders.

${ }^{12}$ See Ott, Riddiogh and Yi (2005) for a discussion of REIT investment and Boudry (2011) and Boudry, Kallberg and Liu (2013) for a discussion of REIT payout policy. 


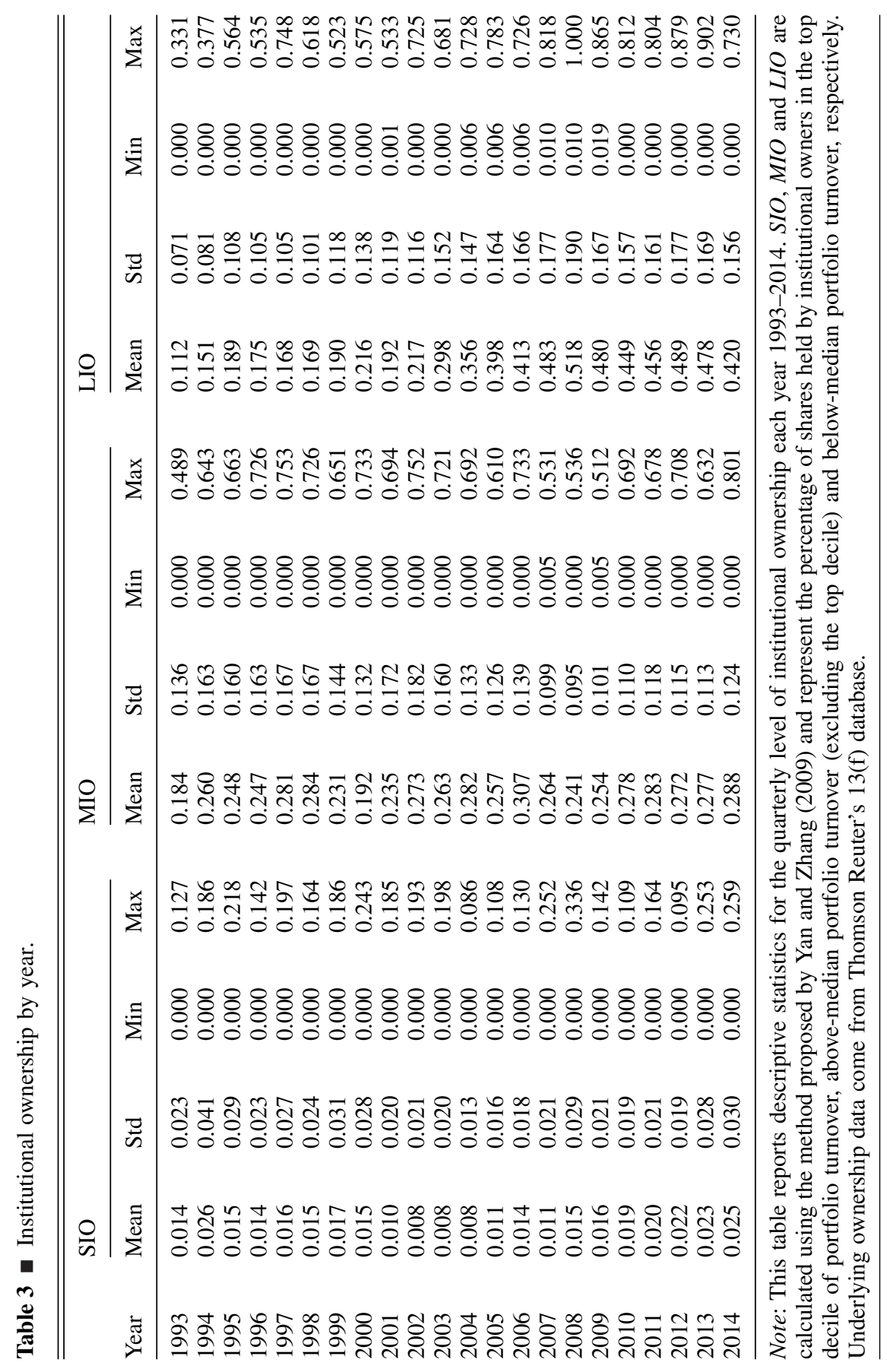




\section{Index Inclusions}

One of the substantial changes in the REIT industry over the sample period has been the inclusion of REITs in major market indices. ${ }^{13}$ In 2001, Equity Office Properties was the first REIT added to the S\&P 500. Since that time, the indexation of the REIT market has been quite dramatic. By 2015, 22 REITs were included in the S\&P 500, 31 were included in the mid-cap S\&P 400 and 31 were included in the small-cap S\&P 600. Inclusion in these indices may explain part of the large increase in LIO after 2001, as REITs entered the portfolios of passive index funds. Index inclusion is likely to improve efficiency by improving microstructure fundamentals, and by increasing information production through higher analyst coverage and institutional ownership. It also likely expands the REIT investor base from those focused on real estate to a larger audience of general equity investors. We obtain S\&P index constituents and addition dates from COMPUSTAT, NAREIT and press releases. $S \& P 500, S \& P 400$ and $S \& P 600$ are dummy variables equal to one if the firm was in one of these respective indexes during the quarter.

\section{Information Pricing}

The quality of the trading environment in which an REIT trades is also likely to have a material impact on how efficiently the firm is priced. To capture these influences, we include several measures from the microstructure literature in addition to dummy variables related to the tick regime and Reg NMS. Tick sizes changed from $1 / 8$ th to $1 / 16$ th on June 23,1997 , from $1 / 16$ th to decimals on January 28, 2001, and the implementation of RegNMS started on July 1, 2007.

Spread to Depth is the ratio of the quoted spread to the quoted depth, both of which are calculated daily from the underlying TAQ data and averaged over the quarter. As Boehmer and Kelley (2009, p. 3755, footnote 18) note, this combined measure is superior to either individual measure entered alone: "a decline in quoted spreads is often associated with a contemporaneous decline in quoted size. In this case, a trader benefits from the decline in spread for part of his intended trade. But for a given trade size, he may be worse off if the supply schedule 'behind' the best quote has become steeper. Alternatively, a trader may simply prefer a larger quoted size at a slightly wider spread." We use the methods outlined in Holden and Jacobsen (2014) to calculate spreads and depth using the TAQ data.

\footnotetext{
${ }^{13}$ See Ambrose, Lee and Peek (2007) and Pavlov, Steiner and Wachter (2017) for a discussion of REIT index inclusions and return behavior.
} 
Illiquidity is likely to negatively impact the efficiency of pricing. Stocks that are hard to trade are less likely to be targeted by arbitrageurs. To capture this effect, we include Amihud, the Amihud (2002) measure as an inverse proxy for the liquidity of a particular REIT. By definition, the Amihud illiquidity measure is given by $|r| / D V O L$, where the numerator is the absolute value of the return on a given day and the denominator is the dollar volume of trade that same day (and is equal to the firm's total market equity value times the firm's share turnover on that day). Using CRSP tape data, we calculate the average of this measure over the quarter for each REIT in the sample.

To capture the effect of trading volume, we include Turnover, the average daily turnover for the company for the quarter from CRSP. If efficiency and institutional ownership are simply driven by trading volume, then this should control for that effect.

Finally, firms that are larger or with higher stock prices may be less costly to trade. To control for this, we include Size, the log of firm market capitalization and Price, the log of the firm's stock price.

\section{Information Production}

Institutions are just one potential avenue of information production for a company. Information production is also likely to be higher around the issuance of securities to the market. REITs that have just issued equity (common or preferred) or debt seem likely to have provided substantial information to the markets in the process of selling new securities. From NAREIT, we gather a complete record of REIT-specific debt and equity issues during the 19932014 period. We use this to construct two dummy variables, Issued Equity and Issued Debt, which indicates for every REIT whether securities were issued in that quarter. ${ }^{14}$ This is a rough proxy for whether the information environment has changed.

From IBES, we extract the record of analyst coverage for each REIT in our sample. Analysts is the number of analysts providing coverage for the REIT in a given quarter. Compared to other public companies, the level of analyst coverage in the REIT universe is quite low. ${ }^{15}$ Higher analyst coverage should be related to more information production, although exactly what effect this

\footnotetext{
${ }^{14}$ See Giacomini, Ling and Naranjo (2017) for a discussion of REIT capital structure choices.

${ }^{15}$ See Downs and Güner (1999), Downs and Güner (2000) and Boudry, Kallberg and Liu (2011).
} 
will have on pricing efficiency is unclear. Boehmer and Kelley (2009) find evidence that analyst coverage may improve pricing efficiency. However, Downs and Güner (1999) and Downs and Güner (2000) find that increased analyst attention in REITs leads to lower liquidity. Lower liquidity should, all things equal, lead to inferior pricing efficiency.

REITs engaged in significant investment or divestment activity are also likely to have a different informational environment from other REITs. To proxy this effect, we include in our analysis Investment, the absolute value of a firm's cash flow from investment activity during the quarter divided by total assets at the start of the quarter. We obtain the firm's total assets from SNL Financial and cash flow from investment activities from COMPUSTAT and the firm's financial statements. We do not lag this variable because the direction of causality is fairly clear. Changes in investment policy should affect firm efficiency, while the opposite is a dramatically harder argument to make.

We also employ two measures from the microstructure literature to examine information production. Quote Changes is the ratio of NBBO quote changes to total NBBO quotes each day (averaged over the quarter). A large number of changes in NBBO quotes relative to the total number of quotes indicates a high information flow for the firm. Quotes to Trades is the ratio of quotes to trades. We compute our quarterly measure by taking the average of the number of NBBO quotes each day (from TAQ) relative to the number of trades (from the CRSP tape). Our measure is similar to an approach taken in Boehmer, Fong and $\mathrm{Wu}$ (2012). A high number of quotes relative to trades suggest greater information flow for the firm. One limitation of these measures is that they may also be driven by the trading strategies of high-frequency traders (HFTs).

The final measure of information production we employ is Rated, a dummy variable indicating whether the firm has a credit rating with any of the three major rating agencies (S\&P, Moody's and Fitch). Firms with credit ratings should, all things equal, have greater information production, although the recent literature casts some doubt on the information content of ratings. ${ }^{16} \mathrm{We}$ obtain rating agency information from SNL Financial.

\section{Descriptive Statistics}

Table 4 reports descriptive statistics for the variables used in the analysis. As expected from Table 3, the average level of TOI is 59.3\%, composed of

\footnotetext{
${ }^{16}$ See, for example, Bolton, Frexias and Shapiro (2012).
} 
Table 4 - Descriptive statistics.

\begin{tabular}{llllll}
\hline \hline Variable & Obs & Mean & Std & Min & Max \\
\hline TIO & 9,164 & 0.593 & 0.283 & 0.000 & 1.000 \\
LIO & 9,164 & 0.315 & 0.195 & 0.000 & 1.000 \\
MIO & 9,164 & 0.262 & 0.144 & 0.000 & 0.838 \\
SIO & 9,164 & 0.016 & 0.026 & 0.000 & 0.336 \\
S\&P 500 & 9,164 & 0.058 & 0.233 & 0.000 & 1.000 \\
S\&P 400 & 9,164 & 0.086 & 0.280 & 0.000 & 1.000 \\
S\&P 600 & 9,164 & 0.103 & 0.304 & 0.000 & 1.000 \\
Amihud & 9,164 & 0.187 & 1.536 & 0.000 & 39.11 \\
Spread to Depth & 9,164 & 0.001 & 0.006 & 0.000 & 0.492 \\
Quote Changes & 9,164 & 0.121 & 0.136 & 0.002 & 1.000 \\
Quote to Trade & 9,164 & 14.76 & 18.31 & 0.016 & 365.8 \\
Turnover & 9,164 & 0.558 & 0.587 & 0.013 & 8.077 \\
Size & 9,164 & 1.834 & 3.560 & 0.003 & 51.70 \\
Price & 9,164 & 26.23 & 20.22 & 0.344 & 184.9 \\
Regime 2 & 9,164 & 0.205 & 0.404 & 0.000 & 1.000 \\
Regime 3 & 9,164 & 0.306 & 0.461 & 0.000 & 1.000 \\
Regime 4 & 9,164 & 0.328 & 0.470 & 0.000 & 1.000 \\
Rated & 9,164 & 0.393 & 0.488 & 0.000 & 1.000 \\
Issued Equity & 9,164 & 0.109 & 0.312 & 0.000 & 1.000 \\
Issued Debt & 9,164 & 0.084 & 0.277 & 0.000 & 1.000 \\
Analysts & 9,164 & 6.498 & 5.304 & 0.000 & 26.00 \\
Investment & 9,164 & 0.092 & 0.137 & 0.000 & 2.543 \\
\hline
\end{tabular}

Note: This table reports descriptive statistics of the explanatory variables used in the analysis. SIO, MIO and $L I O$ are calculated using the method proposed by Yan and Zhang (2009) and represent the percentage of shares held by institutional owners in the top decile of portfolio turnover, above-median portfolio turnover (excluding the top decile) and below-median portfolio turnover, respectively. Underlying ownership data come from Thomson Reuter's 13(f) database. S\&P 500, S\&P 400 and S\&P 600 are dummy variables equal to one if the firm is part of the S\&P 500, S\&P 400 or S\&P 600 during the quarter. Index constituent data are obtained from NAREIT and COMPUSTAT. Amihud is the quarterly average of the daily ratio of absolute returns to dollar volume for each firm calculated from CRSP. Turnover is the quarterly average of daily share turnover calculated from CRSP. Spread to Depth is the quarterly average of the daily quoted spread to quoted depth for each firm calculated from TAQ data. Size is the firm's market capitalization, and Price is the firm's share price. Regime 2, Regime 3 and Regime 4 are dummy variables equal to one if the quarter falls under the 1/16th, decimal or Regulation NMS regimes. The $1 / 8$ th regime is the omitted group. Rated is a dummy variable equal to one if the firm has a credit rating with one of the three major credit rating agencies. Issue Equity and Issue Debt are dummy variables equal to one if the firm issued equity or debt during the quarter. Analysts is the number of analysts covering the firm taken from IBES. Quote Change is the ratio of NBBO quote changes to the total NBBO quotes each day, averaged over the quarter. Quotes to Trades is the ratio of quotes to trades each day, averaged over the quarter. Investment is the absolute value of the firm's cash flow from investment activity during the quarter divided by total assets at the start of the quarter, taken from SNL Financial, COMPUSTAT and firm financial statements. 
$1.6 \%$ short-term owners, $31.5 \%$ long-term owners and the remainder being medium-term owners. For each ownership variable, we observe considerable cross-sectional variation.

On average, between $5 \%$ and $10 \%$ of the sample is in the S\&P 500, the mid-cap S\&P 400 or the small-cap S\&P 600 in any quarter. By the end of our sample period, approximately half of the REITs in the sample are in one of those indices. In total, 81 of the 251 REITs in the sample have been part of a major S\&P index between 1993 and 2014. We conduct difference in means $t$-tests of the REITs included in an index versus those not, and find the included REITs tend to be more efficient. For S\&P 500 REITs, the mean difference in $|1-V R| * 100$ is 1.93 with a $t$-statistic of 7.89 , for the S\&P 400 , it is 1.68 with a $t$-statistic of 8.29 and for the S\&P 600, it is 0.89 with a $t$-statistic of 4.67 .

For all of the microstructure variables, we observe a high degree of variation in the sample. The mean level of Amihud is 0.187 , on average $12.1 \%$ of quotes are related to quote changes and there are 14.76 quotes per trade. The average daily turnover in the sample is $0.558 \%$.

Following Boehmer and Kelley (2009), we control for share price and firm size in our analysis. The small-/mid-cap nature of the REIT universe is evident in Table 4, with the average firm size being \$1.83B. Although we concentrate on only one industry, there is a great deal of cross-sectional variation of firm size in the sample. The one caveat is that even the largest firm in the sample has a market cap of only $\$ 51.7 \mathrm{~B}$. This is very much a smallcap/mid-cap sample, but that is also interesting in that most microstructure studies tend to focus on larger firms. At the start of the sample period, the median firm size is in the 25th percentile of NYSE/NASDAQ/AMEX market cap break points. In the latter part of the sample, the median firm size is consistently between the 35 th and 45 th percentile break point each year.

Turning to the information production proxies, we observe that on average $39.3 \%$ of firms in any given quarter have a credit rating with one of the three major rating agencies. Our data show $10.9 \%$ of firms issue equity in any given quarter and $8.4 \%$ issue debt.

On average, an REIT in the sample is covered by 6.49 analysts in any given quarter, although some REITs are not covered at all, while others have over 25 analysts covering them. The level of coverage also varies over the sample period. In fact, analyst coverage is virtually nonexistent in the sample prior to the late 1990s. This is not overly surprising given that during this time 
period, many REITs lacked what Boudry, Kallberg and Liu (2011) show are the common drivers of analyst coverage.

The average ratio of the absolute value of cash flow from investment activity to total assets is $9.2 \%$. The extremes of Investment are also interesting because they represent true economic events. The extreme values of this variable are related to planned liquidations and mergers and acquisitions. While these transactions are not the norm for most firms in most periods, if the goal of the exercise is to understand what drives pricing efficiency, then events such as these may contribute to understanding this phenomenon.

\section{Principal Results}

Table 5 reports our main quarterly estimation results. The dependent variable for all regressions is $|1-\mathrm{VR}| * 100$. The explanatory variables in the analysis related to institutional ownership, analyst coverage and microstructure are all lagged one period. The remaining variables are contemporaneous, because the direction for causality for these variables is more apparent. We include both firm and year fixed effects as specified. ${ }^{17}$ Firm-clustered $t$-statistics are reported in parentheses.

In Model 1 of Table 5, we include only the total level of institutional ownership in the regression. In Model 2, we include the decomposition of TIO into $S I O, M I O$ and $L I O$ to examine the effect of active versus passive institutional owners. Models 3 and 4 examine the effect of firm and year fixed effects on the estimation. In Models 5 and 6, we address the potential for Nickell (1981) bias by removing the lagged dependent variable in Model 5 and reporting bootstrap-bias corrected results following the method of Everaert and Pozzi (2007) in Model 6. ${ }^{18}$

Turning to Model 1 in Table 5, we find that TIO has no effect of pricing efficiency: the coefficient on $T I O$ is small and not significantly different from

\footnotetext{
${ }^{17}$ We have also estimated the models removing the microstructure regime dummy variables and including quarter fixed effects. The results are similar to those reported. We have also removed firm fixed effects and included property type effects for each REIT. The results are similar and none of the property-type dummy variables was significant. ${ }^{18}$ The model presented is a dynamic panel data model because of the inclusion of the
lagged dependent variable. Such models potentially suffer from Nickell (1981) bias
when $N$ is large and $T$ is small. While no standard exists for what qualifies as "large
$N /$ small $T$ " in the literature, our panel is unlikely to fit the definition because of our
large time series, suggesting that Nickell (1981) bias is unlikely to be an issue in our
estimation. This is supported by the consistent results between our main estimation
and estimations excluding firm fixed effects, excluding the lagged dependent variable,
and estimations using the bias correction of Everaert and Pozzi (2007).
} 
24 Aguilar, Boudry and Connolly

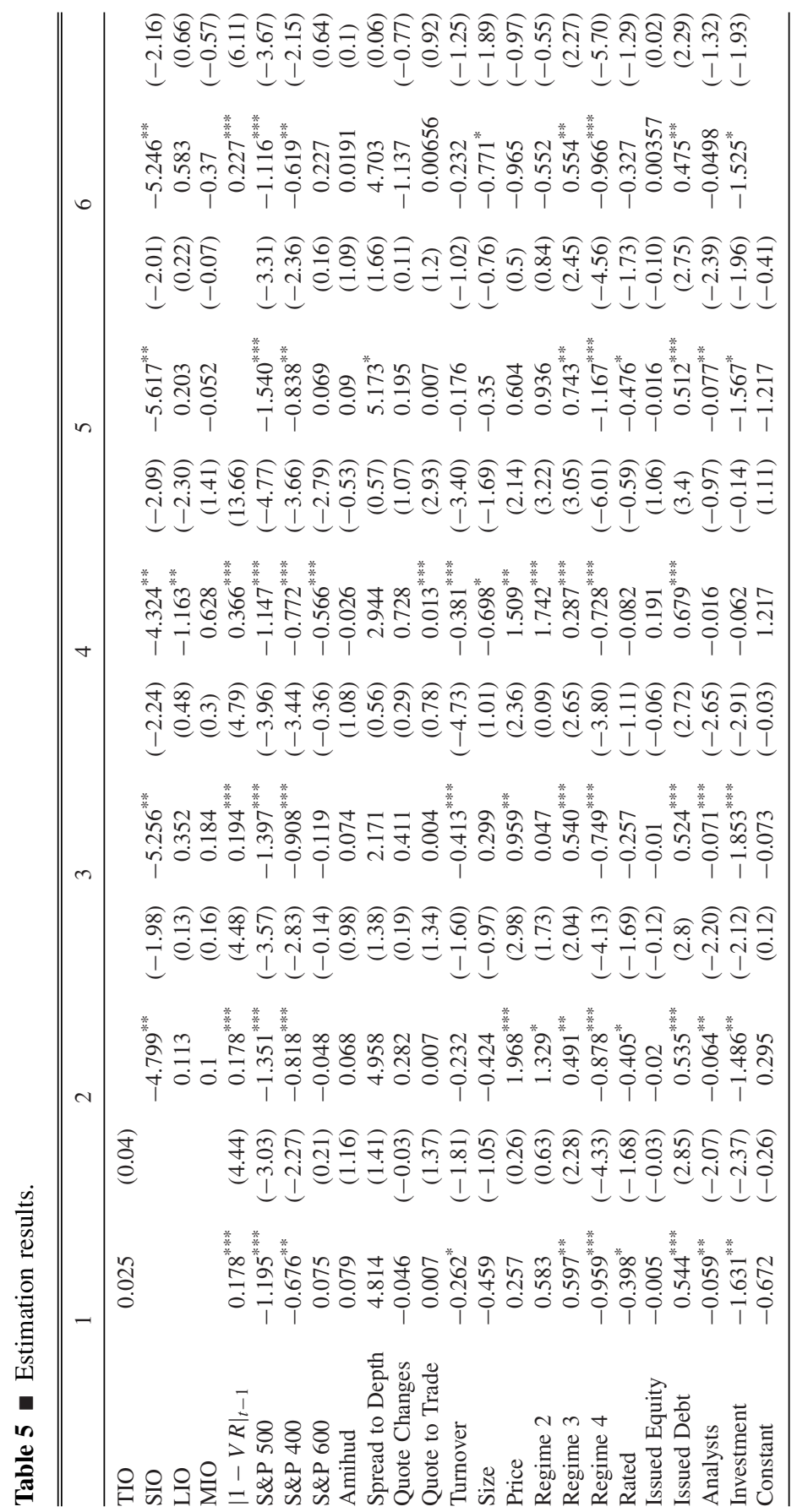




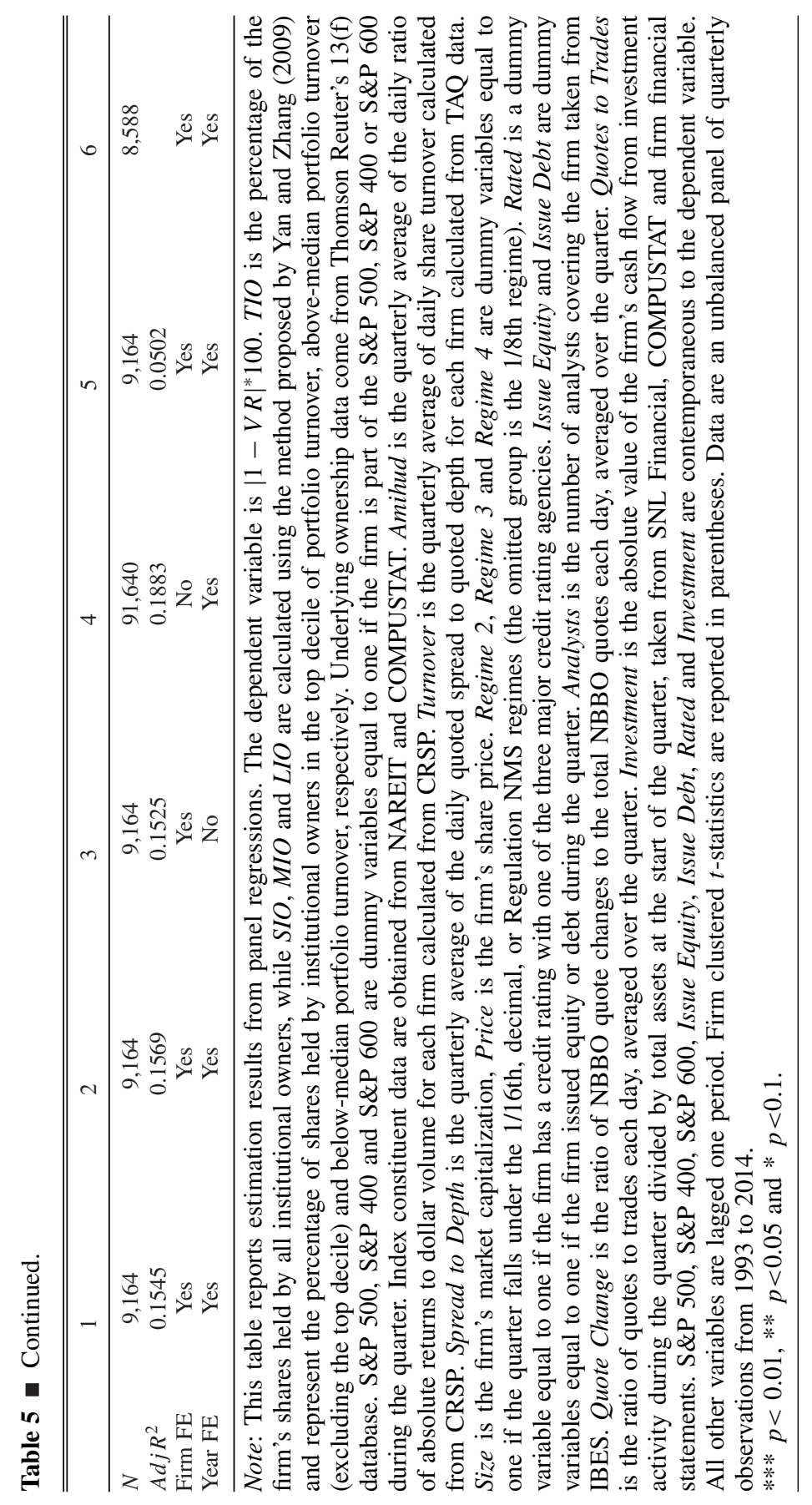


Table 6 Index additions: event analysis.

\begin{tabular}{|c|c|c|c|}
\hline & Obs & $\Delta|1-\mathrm{VR}|$ & $p$-Value \\
\hline \multicolumn{4}{|l|}{ All Indexes } \\
\hline 15-day Windows & 68 & -1.04 & 0.03 \\
\hline 30-day Windows & 68 & -0.93 & 0.06 \\
\hline 60-day Windows & 68 & -1.12 & 0.03 \\
\hline \multicolumn{4}{|l|}{ S\&P 500 Large-Cap } \\
\hline 15-day Windows & 18 & -0.37 & 0.73 \\
\hline 30-day Windows & 18 & -0.83 & 0.22 \\
\hline 60-day Windows & 18 & -1.54 & 0.12 \\
\hline \multicolumn{4}{|l|}{ S\&P 400 Mid-Cap } \\
\hline 15-day Windows & 23 & -1.73 & 0.02 \\
\hline 30-day Windows & 23 & -1.82 & 0.05 \\
\hline 60-day Windows & 23 & -1.00 & 0.31 \\
\hline \multicolumn{4}{|l|}{ S\&P 600 Small-Cap } \\
\hline 15-day Windows & 27 & -0.89 & 0.24 \\
\hline 30-day Windows & 27 & -0.24 & 0.78 \\
\hline 60-day Windows & 27 & -0.96 & 0.26 \\
\hline
\end{tabular}

Note: This table reports mean changes in efficiency around index addition dates. The change in efficiency is measured as the difference in $|1-V R|^{*} 100$ between the postand preestimation windows. $V R$ is the variance ratio estimated in 15-, 30- and 60-day windows before and after the index addition date. A 10-day addition window centered at the addition date is excluded from the analysis. The variance ratios are calculated as (4), where the frequency of sampling of price increments is 15 minutes and $q$ equals 2. Returns are calculated from quote midpoint and quote midpoints are calculated from TAQ data using the methods of Holden and Jacobsen (2014). Index addition dates were collected from COMPUSTAT, NAREIT and press releases. $p$-Values are reported for the test of the null hypothesis that the change is equal to zero.

zero. This is different from Boehmer and Kelley (2009), who find a significantly positive relationship (higher $T I O$ leads to better pricing efficiency). However, the level of $T I O$ may not be as important as the number of active traders. This is especially true for the REIT market, because the level of passive institutional ownership is nearly twice what is observed in a sample of general equities.

We also observe the significant effect of index inclusion on efficiency, especially for the S\&P 500 and mid-cap S\&P 400. S\&P 500 firms are on average $25 \%$ more efficient than nonindex firms, while S\&P 400 firms are on average $15 \%$ more efficient. There is a potential identification issue involved. It is possible that S\&P's selection criteria for index additions are correlated with firm efficiency. To try and disentangle causality, in Table 6, we examine 
changes in efficiency around index inclusion dates. ${ }^{19}$ We calculate variance ratios in 15-, 30- and 60-day windows before and after the index addition date. To avoid potential information leakage issues, we exclude the 10-day window centered around the addition date from our analysis. We then calculate the change in efficiency, $|1-V R|$, between the two estimation windows. If indexes simply add firms that are already efficient, then we would expect to see no significant change between the two estimation windows. On the other hand, if index inclusion does increase efficiency, then we would expect $|1-V R|$ to be smaller in the postaddition window and the change to be negative. Our selection of the size of the estimation windows was driven by two motivations. First, smaller windows around the addition date should enable stronger identification because it gives less time for confounding events to occur. Second, smaller estimation windows are likely to lead to noisier estimates of variance ratios because of limited data. The windows we estimate hopefully balance these two factors.

For the overall sample of index additions (S\&P 500, S\&P 400 and S\&P 600), we find that the change in $|1-V R| * 100$ is $-1.04,-0.931$ and -1.12 in the 15-, 30- and 60-day windows, respectively. These are significantly different from zero at the 5\% level for the 15- and 60-day windows, and significant at the $10 \%$ level for the 30-day window. Given that the average level of $|1-V R| * 100$ reported in the sample is 5.44, they also represent economically meaningful changes. Thus, it appears that inclusion in any major S\&P index improves efficiency. To see if this effect is consistent across indices, we then repeat this exercise for each index. For the S\&P 500, the $15-$, 30- and 60-day changes are $-0.37,-0.83$ and -1.54 . None of these were significantly different from zero at conventional levels. For the S\&P 400 , the 15-, 30- and 60-day changes are $-1.73,-1.82$ and -1.0 . These are significantly different from zero for the 15- and 30-day windows, and represent approximately a $30 \%$ improvement in pricing efficiency compared to the average firm in the sample. Finally, for the S\&P 600, the 15-, 30- and 60 -day changes are $-0.89,-0.24$ and -0.96 . None of these were significantly different from zero at conventional levels.

The results for the changes in efficiency around index inclusions suggest interesting conclusions. Joining the S\&P 500 is not in and of itself beneficial. It appears that the REITs joining this index were already priced efficiently. This may not be surprising given the unique situation the REIT industry went

\footnotetext{
${ }^{19}$ The number of REIT addition dates does not match the number of REITs in an index in the panel sample, because numerous REITs had not elected REIT status at the time they entered an index. That is, they became REITs after they were included in the index.
} 
through in being added to the S\&P 500. Subsequent REIT additions were all large and well known. In this sense, it is not difficult to think that, perhaps, these firms were just always priced efficiently. Similarly, joining the S\&P 600 small-cap index has a minimal effect, likely because these are still very small firms. On the other hand, joining the S\&P 400 mid-cap index appears to be an efficiency-changing event. The results from our panel analysis suggest that these improvements are persistent, even controlling for a myriad of factors (such as turnover, liquidity and institutional ownership) that could explain why being added to the index improves efficiency.

Returning to Table 5, we also find some evidence of the impact of market microstructure on pricing efficiency. The negative coefficient on Turnover shows that firms whose stock trades more frequently are priced more efficiently. ${ }^{20}$ As expected, higher stock prices are associated with better efficiency, because higher prices mean lower percentage transaction costs for fixed tick size. Controlling for other factors, the implementation of Reg NMS tended to have a positive impact on efficiency.

We find some evidence that information production impacts efficiency. The negative coefficient on Analysts indicates that higher analyst coverage is associated with better efficiency. This is consistent with Boehmer and Kelley (2009). The consistency of this result with other public companies shows the integration with the broader capital markets that REITs have experienced in the last decade.

An unexpected result related to information production is the significantly positive coefficient on Issued Debt. Firms issuing debt appear to have inferior pricing efficiency relative to other firms. Our expectation was that the release of information (use of proceeds, etc.) surrounding a debt issuance would lead to better pricing efficiency. To examine this effect more carefully, we compare the pricing efficiency of debt-issuing firms in the quarters before, during and after debt issuance. We find that pricing inefficiency in the period during issuance is significantly larger than the quarter before and the quarter after. There is also no difference in pricing efficiency between the before and after quarters. This suggests debt-issuing firms are not always priced inefficiently, rather they are priced inefficiently in the quarter they issue debt. In fact, in the quarter before and after issuance, they have pricing efficiency that is slightly

\footnotetext{
${ }^{20}$ To examine the joint significance of Turnover and Amihud, we have conducted Wald tests of joint significance. These are significant at the 5\% level only in the models where Turnover was individually significant. If we exclude Turnover from the analysis, Amihud is insignificantly different from zero. We have conducted a similar exercise for Quote Changes and Quotes to Trades and they are only jointly significant in the model excluding firm fixed effects.
} 
better than the average firm in the sample. This suggests that this result is not driven by information production. A more likely explanation is that the firm needed to raise capital, and faced with pricing inefficiency in the firm's equity, the managers chose to issue debt. We know from Boudry, Kallberg and Liu (2010) that REITs will issue debt over equity when they trade at discounts to NAV, so the notion that REIT managers would choose debt over equity as a funding source when their equity is trading inefficiently is quite plausible.

The final result from Model 1 is the negative and significant coefficient on Investment. A one standard deviation increase in Investment is associated with a $3.8 \%$ improvement in pricing efficiency. Given the extreme range of the variable, there is the potential for large economic effects. ${ }^{21}$

To assess whether all institutional owners have the same effect on efficiency, we split TIO into LIO, MIO and SIO in Model 2 of Table 5. The coefficient on $S I O$ is statistically significant, while the coefficients on $L I O$ and $M I O$ are not. Economically, a one standard deviation increase in $S I O$ is related to a $2.3 \%$ improvement in efficiency. In this sense, it appears that it is only the extremely active traders that are driving pricing efficiency in the REIT market. Notice that because of the high range in this variable, individual firm effects could be economically quite large. In unreported results, we examine the sensitivity of this result to the definition of active traders. As expected, as less active traders enter into the definition of $S I O$ by increasing the decile cutoff, the coefficient quickly becomes insignificantly different from zero. Although we do not find evidence that passive institutions (LIO) help efficiency, we also do not find evidence that they decrease it either. This suggests that the large increase in passive institutional ownership that the REIT market has experienced since the inclusion of REITs in the S\&P indices in 2001 has not had a detrimental impact on pricing efficiency in the sector.

In Models 3 and 4, we remove year effects and firm-fixed effects. Removing these effects does not change the main results we have previously discussed. Similarly, using the bias-corrected estimation technique of Everaert and Pozzi (2007) in Model 6 does not change our conclusions. This once again suggests that Nickell (1981) bias is not a serious issue in our estimation.

\section{Conclusion}

Using individual REIT pricing data, we estimate the time-varying distribution of REIT-level variance ratios covering the 1993-2014 period. Our motivation

\footnotetext{
${ }^{21}$ In unreported results, we have also included dummy variables for M\&A activity in the estimation. These were all insignificantly different from zero.
} 
for examining the REIT market is twofold. First, there is scant evidence on the firm-level efficiency of the REIT market. Those papers that do exist focus primarily on market-level efficiency. While interesting, both participants in the market and managers face firm-level decisions. So, it is efficiency at this level that is important to these groups. Second, while the finance literature has examined efficiency for general equities, these studies exclude REITs. Given the unique nature of both the REIT business model compared to general equities, and also the extreme changes that have occurred in the industry during the sample period, it is not obvious that prior results can be easily extended to the REIT market.

Our estimates show that the average REIT is efficiently priced, but there are many REITs that are clearly not efficiently priced at any given point in time. We find examples of both persistence and mean reversion in the returns of individual REITs.

Following the approach of Boehmer and Kelley (2009), we also examine the determinants of deviations from pricing efficiency. We find that a higher level of ownership by active institutional investors is associated with improved pricing efficiency. While passive institutional investors do not appear to improve efficiency, we find no evidence that they hurt efficiency. This indicates that the dramatic increase in passive institutional ownership in the REIT market has not been detrimental to the efficient pricing of the sector.

One of the unique changes in the REIT market during our sample period has been the addition of REITs to major market indices. Prior to 2001, REITs were excluded from all $\mathrm{S} \& \mathrm{P}$ indices. We find that REITs that are part of the S\&P 500 or S\&P 400 (but not the S\&P 600) are more efficiently priced than other REITs. Examining changes in efficiency around index inclusion dates, we find that the result for the S\&P 500 REITs is likely driven by sample selection, because there is no significant change in efficiency for firms that enter this index. This is consistent with the notion that REITs added to the S\&P 500 are in some sense unique. They are large by REIT market standards, and also have significant investor attention before they were added to the index. For the mid-cap S\&P 400, we find significant improvements in efficiency around index inclusion. The change in efficiency for these firms is likely due to the large change in investor exposure that entering this index provides. These firms go from small-cap obscurity into the mid-cap universe of firms. We find no change in efficiency for the small firms in the S\&P 600.

In August 2016, MSCI and S\&P created the 11th Global Industry Classification Standard (GICS) sector that separates real estate stocks from financials. Although the event is outside of our sample period, the results of our article do 
suggest some likely consequences from this event. To the extent that separating real estate from financials increases institutional ownership, this is likely to only have a net positive impact on efficiency for REITs. The degree of this impact will be determined by the composition of the institutions that trade the new GICS. If these are simply passive index funds and the GICS becomes the index they track, then this is unlikely to improve efficiency. However, if it attracts more active managers, then this is likely to improve efficiency. Our results related to index inclusions suggest minimal effects. The REITs that are already indexed (which is a substantial portion of the industry) already trade quite efficiently. Our insignificant results for the small firms entering the S\&P 600 suggest that the remaining small REITs that are not in any index presently are unlikely to benefit from simply being part of the new GICS. We leave a complete examination of this event to future research.

From an information production perspective, we find that increased analyst coverage has a beneficial impact on pricing efficiency. Finally, we find some evidence that firms involved in investment or divestment activity during a quarter tend to be priced more efficiently. Overall, our results add to our understanding of pricing efficiency in the REIT market, especially at the firm level.

We would like to thank seminar participants at the 2015 NAREIT-AREUEA Real Estate Research Conference, Lehigh University and AREUEA 2016 (San Francisco), Jennifer Conrad, Libo Sun (AREUEA discussant), Andrey Ukhov, Abdullah Yavas (Editor) and an anonymous referee for comments. We would also like to thank Merhdad Samadi and Boone Bowles for excellent research assistance. A previous version of this article circulated under the title "The Dynamics of REIT Market Efficiency.” All errors are our own.

\section{References}

Ambrose, B., D. Lee and J. Peek. 2007. Comovement After Joining an Index: Spillovers of Nonfundamental Effects. Real Estate Economics 35: 57-90.

Amihud, Y. 2002. Illiquidity and Stock Returns: Cross-Section and Time-Series Effects. Journal of Financial Markets 5: 31-56.

An, H., Q. Wu and Z. Wu. 2016. REIT Crash Risk and Institutional Investors. The Journal of Real Estate Finance and Economics 53(4): 527-558.

Boehmer, E., Y. Fong and J. Wu. 2012. International Evidence on Algorithmic Trading. Working Paper.

and E. Kelley. 2009. Institutional Investors and the Informational Efficiency of Prices. Review of Financial Studies 22: 3566-3594.

Bolton, P., X. Frexias and J. Shapiro. 2012. The Credit Ratings Game. Journal of Finance 67: 85-111.

Boudry, W.I. 2011. An Examination of REIT Dividend Payout Policy. Real Estate Economics 39: 601-634. 
J. deRoos and A. Ukhov. 2016. Diversification Benefits of REIT Preferred and Common Stock: New Evidence from a Utility based Framework. Real Estate Economics, Forthcoming. https://doi.org/10.1111/1540-6229.12166

J.G. Kallberg and C.H. Liu. 2010. An Analysis of REIT Security Issuance Decisions. Real Estate Economics 38: 91-120.

and 2011. Analyst Behavior and Underwriter Choice. Journal of Real Estate Finance and Economics 43: 5-38.

Journal of Corporate Finance 23: 23-38.

Bushee, B. 1998. The Influence of Insitutional Investors on Mypoic R and D Investment Behavior. Accounting Review 73: 305-333.

Campbell, J., A. Lo and A. MacKinlay. 1997. The Econometrics of Financial Markets. Princeton, NJ: Princeton University Press.

Charles, A., and O. Darne. 2009. Variance-Ratio Tests of Random Walk: An Overview. Journal of Economic Surveys 23: 503-527.

Ciochetti, B., T. Craft and J. Shilling. 2002. Institutional Investors' Preferences for REIT Stocks. Real Estate Economics 30: 567-593.

Conrad, J., S. Wahal and J. Xiang. 2015. High Frequency Quoting, Trading, and the Efficiency of Prices. Journal of Financial Economics 116: 271-291.

Devos, E., S. Ong, A. Spieler and D. Tsang. 2013. REIT Institutional Ownership Dynamics and the Financial Crisis. Journal of Real Estate Finance and Economics 47: 266-288.

Downs, D. 1998. The Value in Targeting Institutional Investors: Evidence from the Five-or-Fewer Rule Change. Real Estate Economics 26: 613-649. and Z. Güner. 1999. Is the Information Deficiency in Real Estate Evident in Public Market Trading? Real Estate Economics 27: 517-541.

and - 2000. Investment Analysis, Price Formation and Neglected Firms: Does Real Estate Make a Difference? Real Estate Economics 28: 549-579.

Everaert, G., and L. Pozzi. 2007. Bootstrap-Based Bias Correction for Dynamic Panels. Journal of Economic Dynamics and Control 31: 1160-1184.

Giacomini, E., D. Ling and A. Naranjo. 2017. REIT Leverage and Return Performance: Keep Your Eye on the Target. Real Estate Economics, Forthcoming.

Holden, C., and S. Jacobsen. 2014. Liquidity Measurement Problems in Fast, Competitive Markets: Expensive and Cheap Solutions. Journal of Finance 69: 1747-1785.

Jirasakuldech, B., and J. Knight. 2005. Efficiency in the Market for REITs: Further Evidence. Journal of Real Estate Portfolio Management 11: 123-132.

Kaul, G. and M. Nimalendran. 1990. Price Reversals: Bid-Ask Errors or Market Overreaction? Journal of Financial Economics 28: 67-93.

Ke, B., and K. Petroni. 2004. How Informed Are Actively Trading Institutional Investors? Evidence from Their Trading Behavior before a Break in a String of Consecutive Earnings Increases. Journal of Accounting Research 42: 895-927.

Krouse, S., D. Benoit and T. McGinty. 2016. Passive Funds Embrace Their New Power. Wall Street Journal (25th October), A1-A12.

Kuhle, J., and J. Alvayay. 2000. The Efficiency if Equity REIT Prices. Journal of Real Estate Portfolio Management 6: 349-354.

Lo, A., and A.C. Mackinlay. 1988. Stock Market Prices Do Not Follow Random Walks: Evidence from a Simple Specification Test. Review of Financial Studies 1: 41-66. 
MacKinnon, G., and A.A. Zaman. 2009. Real Estate for the Long Term: The Effect of Return Predictability on Long-Horizon Allocations. Real Estate Economics 37: 117-153.

Nelling, E., and J. Gyourko. 1998. The Predictability of Equity REIT Returns. Journal of Real Estate Research 16: 251-268.

Nickell, S. 1981. Biases in Dynamic Models with Fixed Effects. Econometrica 49: 1417-1426.

Niederhoffer, V., and M. Osborne. 1966. Market Making and Reversal on the Stock Exchange. Journal of the American Statistical Association 61: 897-916.

O'Hara, M. and M. Ye. 2011. Is Market Fragmentation Harming Market Quality? Journal of Financial Economics 100: 459-467.

Ott, S., T. Riddiogh and H. Yi. 2005. Finance, Investment and Investment Performance: Evidence from the REIT Sector. Real Estate Economics 33: 203-235.

Pavlov, A., E. Steiner and S. Wachter. 2017. The Consequences of REIT Index Membership for Return Patterns. Real Estate Economics, Forthcoming. https://doi.org/10.1111/1540-6229.12202

Roll, R. 1984. A Simple Implicit Measure of the Effective Bid-Ask Spread in an Efficienct Market. Journal of Finance 39: 1127-1139.

Schindler, F., N. Rottke and R. Füss. 2010. Testing the Predicatbility and Efficiency of Securitized Real Estate Markets. Journal of Real Estate Portfolio Management 16: 171-192.

Seck, D. 1996. The Substitutability of Real Estate Assets. Real Estate Economics 24: $75-95$.

Stambaugh, R. 1999. Predictive Regressions. Journal of Financial Economics 54: 375-421.

Stevenson, S. 2002. Momentum Effects and Mean Reversion in Real Estate Securities. Journal of Real Estate Research 23: 47-64.

Yan, X. and Z. Zhang. 2009. Institutional Investors and Equity Returns: Are ShortTerm Institutions Better Informed? Review of Financial Studies 22: 893-924. 